\title{
Stress distribution in column-plate foundations of Monument of Christ The King erected in Świebodzin
}

\author{
Jakub Marcinowski ${ }^{1}$,Volodymyr O. Sakharov ${ }^{2}$ \\ Institute of Civil Engineering, University of Zielona Gora, \\ 1, Szafrana str., 65-516 Zielona Gora, Poland, \\ 1 j.marcinowski@ib.uz.zgora.pl, orcid.org / 0000-0001-6834-0843 \\ 22v.sakharov@ib.uz.zgora.pl, orcid.org / 0000-0002-9381-3283
}

DOI: $10.32347 / 0475-1132.40 .2020 .37-47$

\begin{abstract}
The paper presents results of numerical simulations of the stress distribution and deformations within of foundations of huge monument of Christ The King erected in Świebodzin (Poland) in 2010. It is 3 meters taller than the better known statue of Christ the Redeemer in Rio de Janeiro, standing at 30.1 meters tall without its pedestal.

Foundations were built as a system of reinforced concrete columns and slabs which can be classified as a spatial column-slab system. Actual mechanical parameters of the substrate and of the artificial mound made of field stones, sand, gravel and clay were adopted in calculations. The numerical simulations of structural members of foundation and determination of the stress distribution are presented in the article. Monument itself was not included into the model. Instead of it the rigid cantilever was introduced to which resultant forces were applied. Three different stages were distinguished: the initial state after foundation and mound accomplishment, the initial state plus the dead load and the initial state plus the dead load and the wind load. It was assumed that the wind load was taken into account in a quasi-static formulation by applying the equivalent horizontal force and the torque. Stresses and displacements for these three stages were determined by Finite Element Method using Simulia ABAQUS system. It was disclosed what was a contribution of particular parts of foundations in sustaining loads in considered load cases. The state of exertion of structural members of foundations and the soil itself was assessed.

It was showed that the column-slab foundations and soils of the mound play important role in taking loads of the statue, spreading them and safe
\end{abstract}

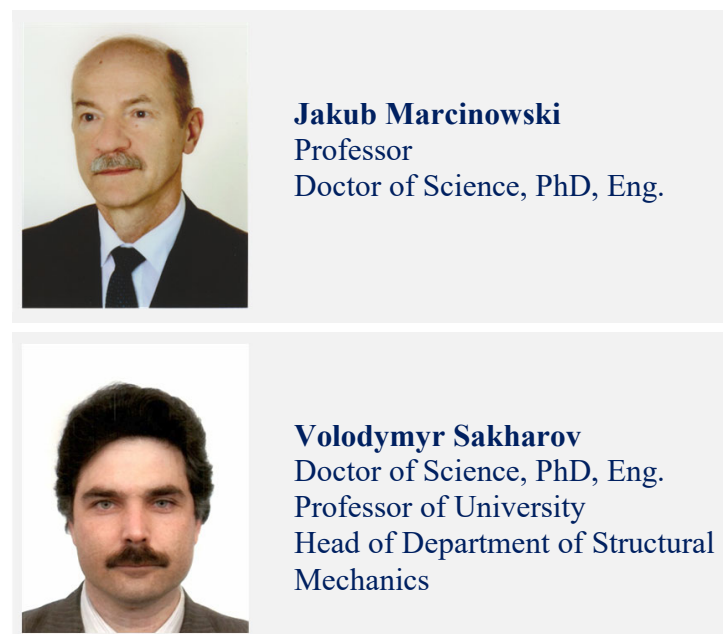

transferring to the undisturbed level of natural soils. According to the numerical simulations results the columns of foundation take as much as $64 \%$ of the vertical load (in the most unfavourable load conditions). At the same time soils of the mound take through the side surface of piles about $20 \%$ of the vertical load.

Keywords: Christ The King, foundations, column-slab system, monument, artificial mound, numerical simulations. 


\section{INTRODUCTION}

The statue of Jesus Christ the King of the Universe was erected in Świebodzin, small town in western part of Poland (see fig. 1) on the 6th of November 2010. The construction took six years and now takes its place as the Largest Statue of Jesus Christ according to the Guinness Book of World Records, [1]. It is 3 meters taller than the better known statue of Christ the Redeemer in Rio de Janeiro, standing at 30.1 meters tall without its pedestal. The figure is 33 meters high (plus $2 \mathrm{~m}$ the gilded crown) and it weighs 260 tons [2]. The head alone is $4.5 \mathrm{~m}$ tall and weighs about 3 tons. The crown is 3.5 metres in diameter and nearly $2 \mathrm{~m}$ in height and is gilded. The distance between the ends of the fingers is 26.1 meters. The statue was built on a 11.5 meter heap of stones and soil and along with this mound, it reaches 47.5 meters overall.

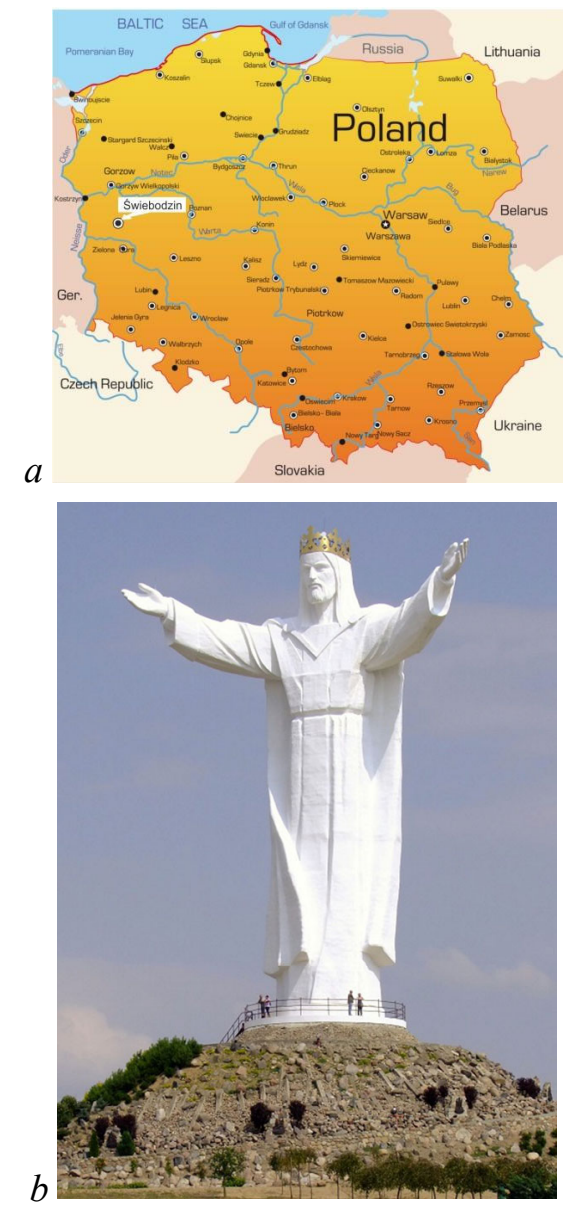

Fig.1. Monument of Christ the King:

a) location of the Świebodzin town, b) general view of the statue
The project was conceived and led by $\mathrm{S}$. Zawadzki, a retired Polish priest. The sculpture design was primarily produced by M. K. Patecki. The small (2.5 $\mathrm{m}$ high) figure made of plaster was scanned and this scan was the source geometry used in the design. Lower segments of the statue were made of shotcrete and upper were fabricated from glass fibre reinforced polymer. The whole statue was reinforced by steel, internal spatial truss (see fig. 2a). The external wall of the monument was connected with this internal truss by steel bars. Arms were reinforced by the additional, steel spatial truss.

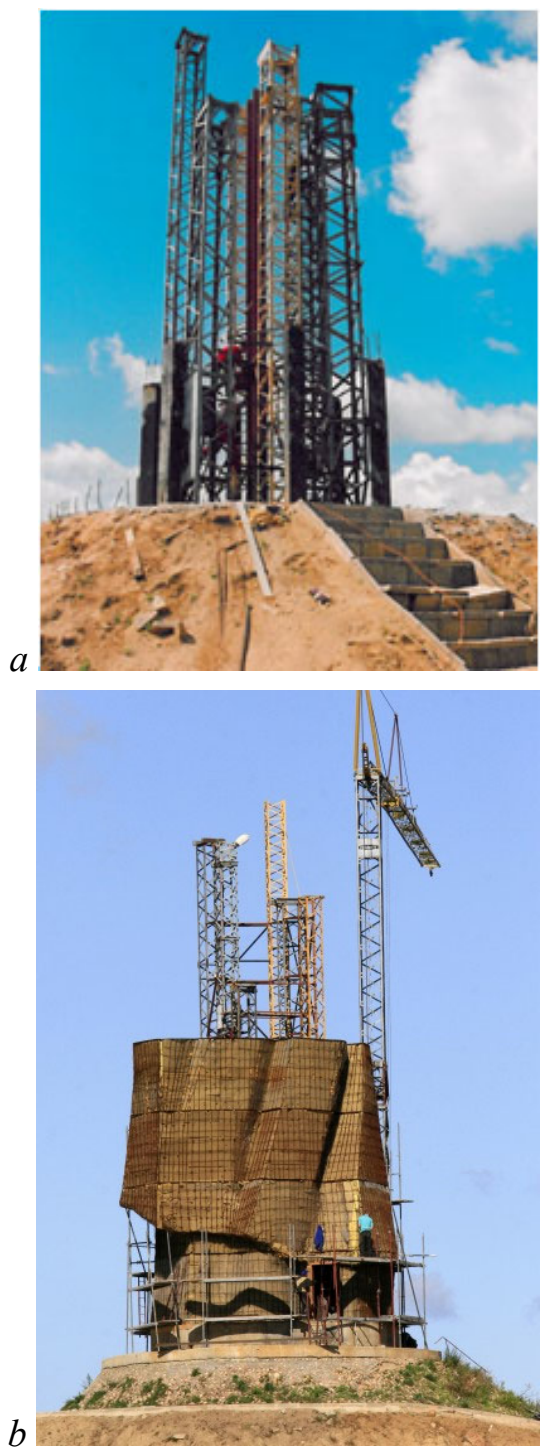

Fig.2. Statue of Christ the King during the erection: a) internal spatial truss, b) initial wall segments before shotcreting 
The figure itself were analysed earlier (comp. [3-6]) and is out of the scope of this paper. The structural solution of foundations is not exceptional. The similar column-slab foundations were considered in [7].

In this paper the numerical simulations of structural members of foundation are presented and determination of the stress distribution beneath the statue's base was the main objective of this work.

\section{FOUNDATION SOLUTION OF THE STATUE}

The first structural element of foundations was placed $14 \mathrm{~m}$ below the feet of the figure of the Christ the King. It was the rectangular concrete plate of thickness $0.4 \mathrm{~m}$ and $6.3 \mathrm{~m}$ side length. Foundation plate base is located one meter below the surface of the natural relief, buried at $0.5 \mathrm{~m}$ into the bearing layer 1 . On this plate six precast concrete columns were erected at vertices of the hexagon inscribed in a circle of diameter of $5.2 \mathrm{~m}$. Columns were $10 \mathrm{~m}$ long. After their erection the mound/heap was created from filled up soil which was a mixture of sand and clay, fieldstones and smaller or greater pieces of building materials. The filled up soil was compacted (however resulting soil density is not known).

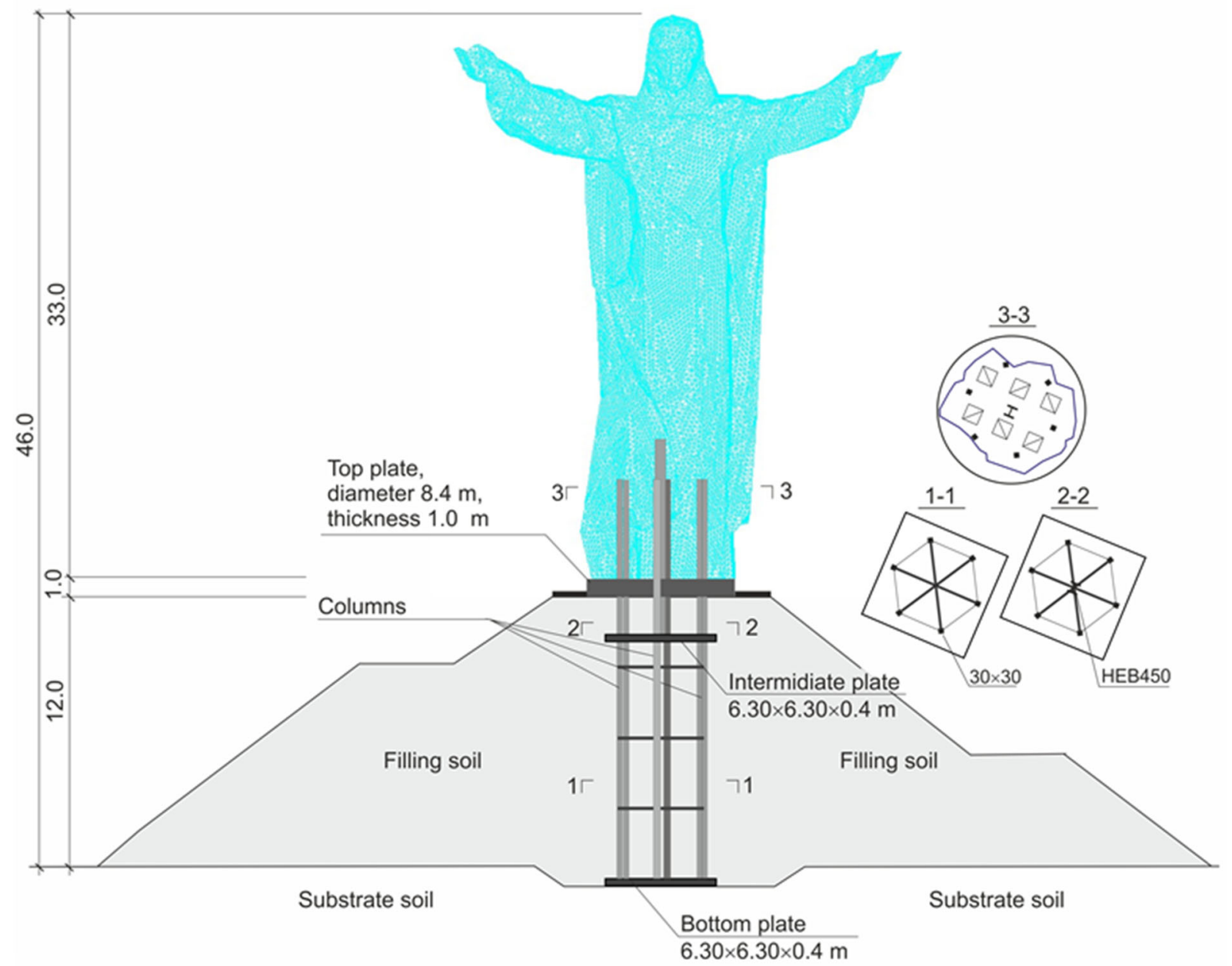

Fig.3. Schematic view of the foundation construction

At the level of $10 \mathrm{~m}$ from bottom all columns were connected by the other reinforced concrete plate (see Fig. 3). On this plate six Other columns of $6 \mathrm{~m}$ long were erected as a continuation of their counterparts located below. These columns were interconnected by steel bars of CHS section. On the level of footing the main concrete plate of $8.6 \mathrm{~m}$ diameter 
and $1.0 \mathrm{~m}$ thickness was casted. Fig. 4 presents the lower part of foundations. Fig. 5 shows the top plate, reinforced concrete columns emerging from it and steel trusses being the part of inner, spatial structure.
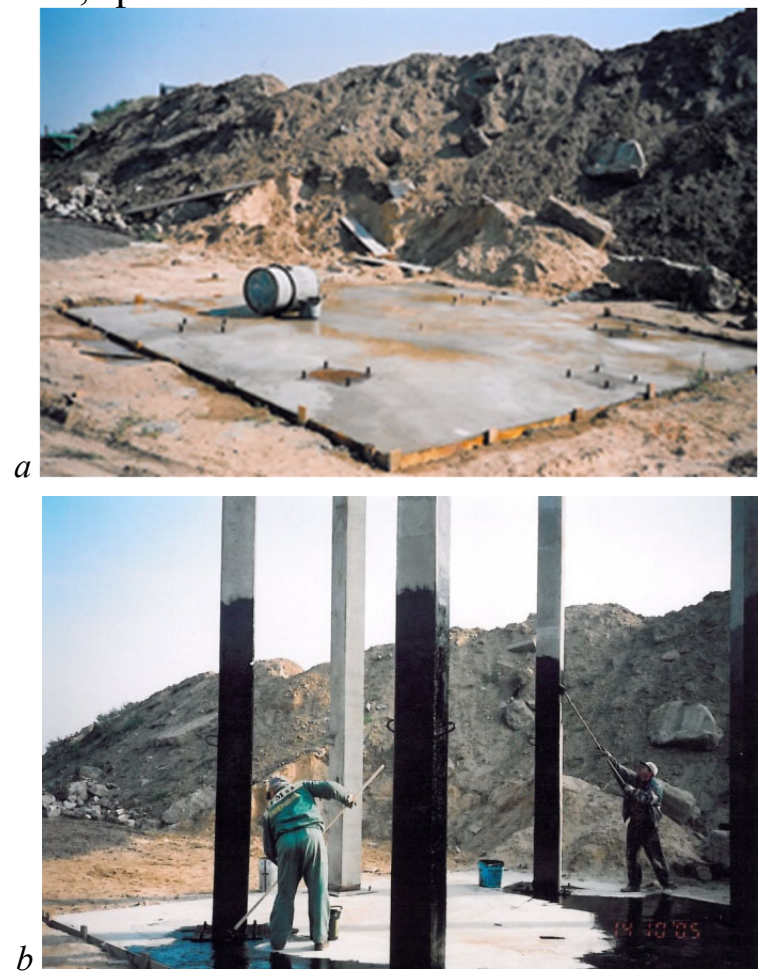

Fig.4. Lower part of foundations: a) bottom plate, $b$ ) lower segments of columns

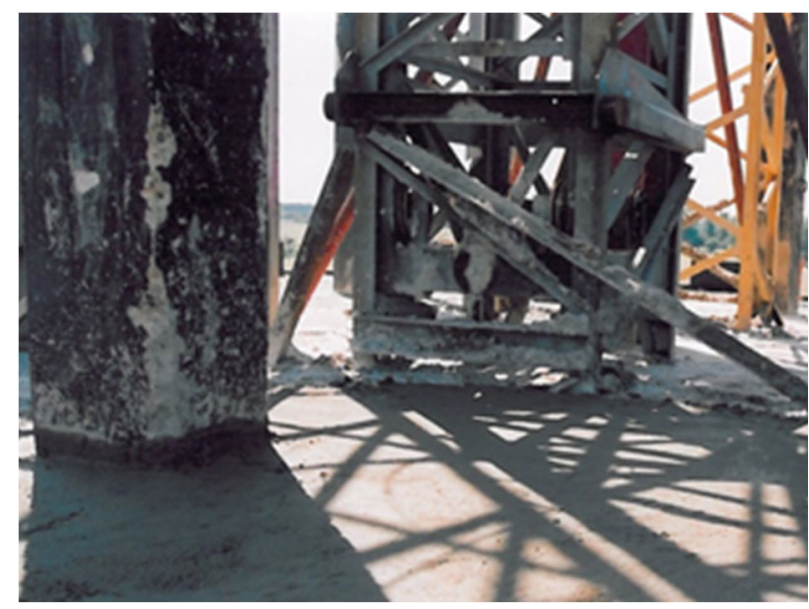

Fig.5. The top plate after concrete casting

The total height of the mound was $12 \mathrm{~m}$ with a slope of 1:2.

To ensure the contact of foundation structures with the soil of the mound, injector pipes were installed as part of the upper plate structure. When necessary (and as part of maintenance) those pipes are used to inject water- sand mixture in order to fill any voids formed as a result of mound settlement, erosion or other processes. This guarantees a constant contact of the foundation with the artificial base, ensuring that foundation can adopt and transfer the load from the structure of the monument to the ground base under both static and dynamic loads.

\section{GEOLOGICAL SITUATION (PROFILE)}

The ground soil conditions have been recognized to a depth of $12 \mathrm{~m}$. In terms of geomorphology, the area where Statue is located, is the object of the Lagow Lake District.

Quaternary sediments formed in two fractions: glacial, sandy clay and glaciated clay mainly sands. The geological profile was presented at (Fig. 6)

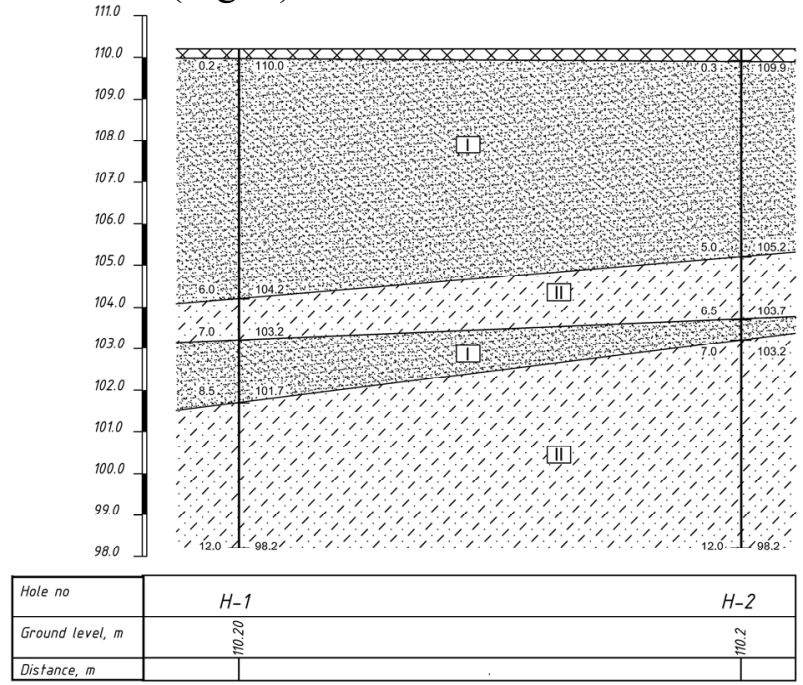

Fig.6. The geological profile

Directly, below the surface, there is a soil layer of $0.2-0.3 \mathrm{~m}$. Then, two geotechnical layers were recognized: medium squeak layer (No. I) with gravel admixtures or sanded clay. These sands are in a medium-compacted condition, with a density of $\mathrm{I}_{\mathrm{D}}=0.6$ (saturation $\mathrm{W}=14 \%$, density $\rho=1.85 \mathrm{t} / \mathrm{m}^{3}$, internal friction angle $\varphi=34^{\circ}$, eodometer compressibility modulus $\mathrm{M}_{0}=113 \mathrm{MPa}$, secant modulus of elasticity $E=95 \mathrm{MPa}$ ); a layer of silty sands (No. II) is in the hard plastic state, with an $\mathrm{I}_{\mathrm{L}}=0.1$ plasticity (saturation $\mathrm{W}=12 \%$, density $\rho=2.2 \mathrm{t} / \mathrm{m}^{3}$, internal friction angle $\varphi=20^{\circ}$, eodometer com- 
pressibility modulus $\mathrm{M}_{0}=47 \mathrm{MPa}$, secant modulus of elasticity $\mathrm{E}=36 \mathrm{MPa}$ ).

In the examined area, the occurrence of groundwater has not been found.

\section{FINITE ELEMENT MODEL}

To assess stress-strain state of load carrying (bearing) components of the statue foundations, the numerical model of the structure interaction with soil substrate was created. To this end the Simulia ABAQUS system was used.

The finite element model was composed of the soil substrate adopted according to the geological profile, the mound piled with a bulk soil, plates and columns creating the load carrying structure of the Statue (see Fig. 7). Model also assumed round foundation slabs. The total range the soil substrate incorporated into the model was chosen after taking into account preliminary numerical simulations [2]. In order to analyse various load combinations, finite element model contained both symmetrical parts. The statue itself was removed from the numerical model but all forces coming from the statue due to its weigh and the equivalent wind action were applied to the upper constructions.

The values of material parameters used in simulation are given in table 1 .

Table 1. Material parameters

\begin{tabular}{|r|r|r|r|}
\hline Material & E, MPa & $v$ & $\rho, \mathrm{t} / \mathrm{m}^{3}$ \\
\hline Soil (1) & 95 & 0.3 & 1.85 \\
\hline Soil (2) & 36 & 0.4 & 2.2 \\
\hline Mound (3) & 40 & 0.3 & 2.0 \\
\hline Concrete & 30000 & 0.2 & 2.5 \\
\hline Steel & 200000 & 0.28 & 7.85 \\
\hline
\end{tabular}

All structural elements were modelled using spatial FEs (C3D8I) with enhanced convergence. All structural elements, soil, mound were fully conjugated at the nodes. Interaction of the construction elements with the soil was also modelled at the nodes. The density of the
FE grid was selected based on the preliminary calculations.

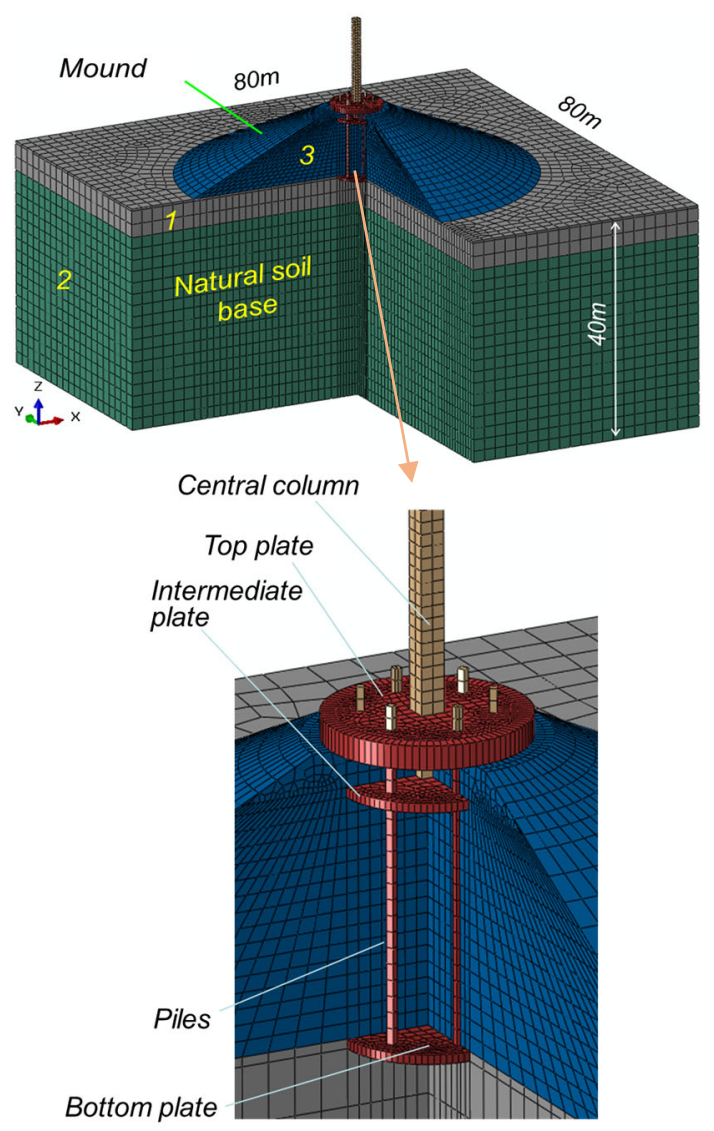

Fig.7. Finite element model of the bearing part of the monument

In order to reduce influence of the boundary conditions, the size of the soil segment was set at $80 \mathrm{~m} \times 80 \mathrm{~m}$ with $40 \mathrm{~m}$ depth. According to the geological profile, two layers were used: the carrier (bearing) layer - a medium density sand with $5.2 \mathrm{~m}$ thickness and a sandy loam. Preliminary studies have shown that the load on the substrate is predominantly evenly transferred, and additional stresses at the base of the structure decrease rapidly. Taking into account the low deformation of the sand and the considerable thickness used for the model, the layer 2 was extended to the cover remaining thickness of the massif.

\section{LOADING AND MODELLING STAGES.}

To take into account the evolution of the stress-strain state of the elements of the "foundation-building-construction" system, the sim- 
ulation was carried out in sequential, deliberately defined stages.

In the first stage erection of the mound was modelled and it was assumed that all structural members of foundations and namely piles/columns, bottom, intermediate and upper plates were assembled earlier. Construction of the statue and the hill took quite a long time. This allows to assume that rheological processes caused by the redistribution of the stressed-deformed state due to the weight of the foundation structures and the mound have ended. Thus, obtained state of stresses and deformations was adopted as the initial one.

In the next stage of calculations the influence of the whole structure was taken into account. The dead load $\left(\mathrm{F}_{\mathrm{v}}\right)$ of the whole statue was applied at the projection of the gravity centre (fig 8).

The wind load was accounted for in the subsequent stage. Within the framework of this study, it was assumed that the wind load was taken into account in a quasi-static formulation by applying the equivalent horizontal force $\left(F_{h}\right)$ and the torque. In actual conditions, the wind load in predominantly operates in the opposite direction from the eccentricity of the centre of gravity of the monument. To estimate the most unfavourable influence from the wind, the horizontal load $\mathrm{F}_{\mathrm{h}}$ was applied in the direction of the eccentricity. The values of forces were: $F_{v}=2505 \mathrm{kN}, F_{h}=750 \mathrm{kN}$.

In order to justify the model of the ground environment, preliminary studies of soil behaviour were carried out. To achieve this, simulation was carried out using the nonassociated law of the Mohr-Coloumb criterion. It should be noted that the criterion of plasticity and deformation (including dilatancy angle) substantially affect the convergence of the solution. Given that for the mound there is no available information on the actual state of the soil, unambiguous acceptance of the criteria for it is extremely difficult. However, the results showed that under conditions of achieved equilibrium (which corresponds to real conditions), plastic deformations do not arise in the primary mass of the soil. At different stages, local supercritical state zones appear either on the edges of the plates (Fig. 9) or near the surface of the slope. This behaviour can be explained by the distorted geometry of the FE and a small average stress in the soil, which results in a low threshold of plastic deformations. Solving problems with such effects requires more precise finite element mesh and a smaller load steps when applying nonlinear solution algorithms. Both of those will significantly increase calculation time.

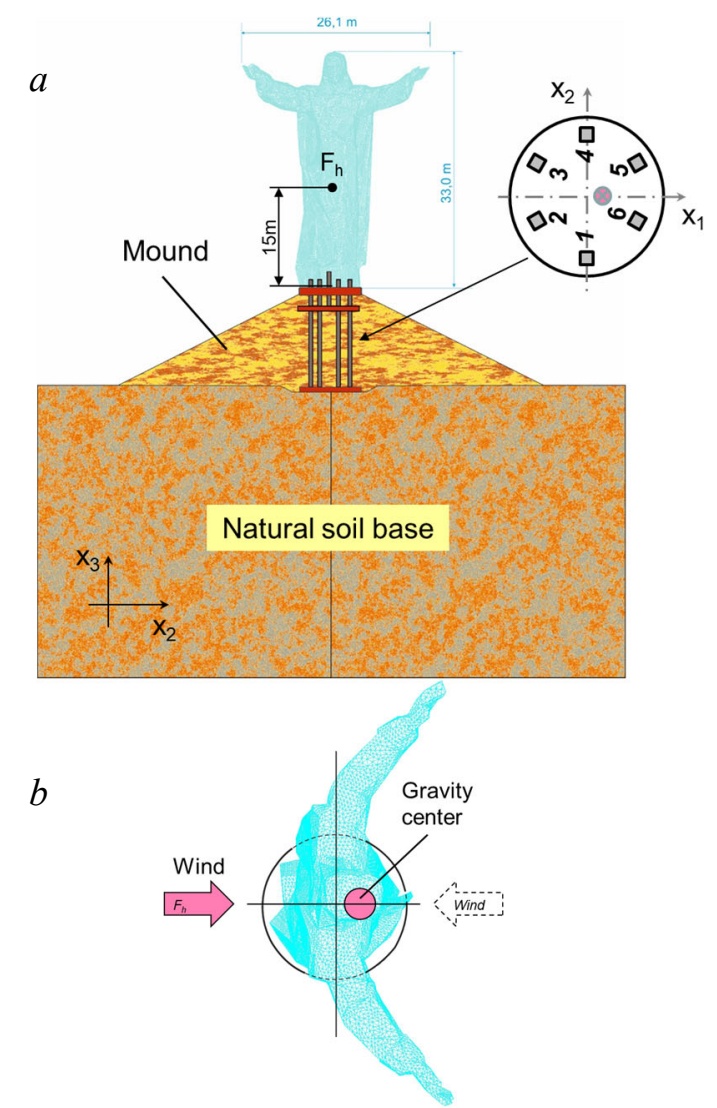

Fig. 8. Loading scheme: location of horizontal force $F_{h}, b$ - wind direction and gravity centre ( $F_{v}$ location)

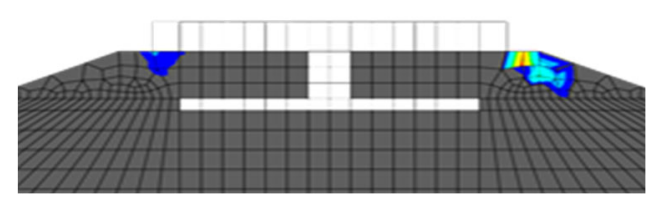

Fig. 9. Plastic zone distribution after $\mathrm{F}_{\mathrm{h}}$ loading

However, the analysis has revealed that additional loads from the monument lead to a small additional load of the base, which will be discussed in detail in the next section. FE in the plastic state were all located in the separate local zones and did not influence the overall 
picture of the interaction of the structure with the base.

Taking into account the insignificance of the manifested postcritical behaviour and the lack of reliable information on soil parameters (in particular for the mound), remaining analyses have adopted models consistent with the linear theory of elasticity.

\section{CALCULATIONS RESULTS}

\section{Initial Stage.}

At the initial stage, the stress state in soils and foundations was determined during the erection of the mound. Piles connected to the lower plate to further stability were further strengthened by spatial bars, forming a spatial frame. Then, the stiffnesses of the middle and upper plates were added. During construction, the soil of the mound was compacted. The middle and upper monolithic reinforced concrete slabs were made directly on the soil of the mound. Therefore, the load induced by the weight of the slabs, because of the low stiffness (before concrete is set) is transferred mainly to the soil and practically does not participate in the loading of the piles. In the simulation, this was taken into account by adopting reduced elastic moduli, with the subsequent restoration of the material properties at subsequent stages. Such approach allowed to take into account the formation of a stressed state in the mound and the soil base.

Simulation has shown that loading from the mound led to the formation of an area of increased compression stresses above the lower plate and on the contour under the plate with stresses in the range 0.18-0.20 MPa (Fig. 10). In this case, due to the uniform loading around the slab with soil, the shear stresses in this zone are insignificant (about $12 \mathrm{kPa}$ ). The level of compressive stresses in the zone of the middle plate was about $40 \mathrm{kPa}$.

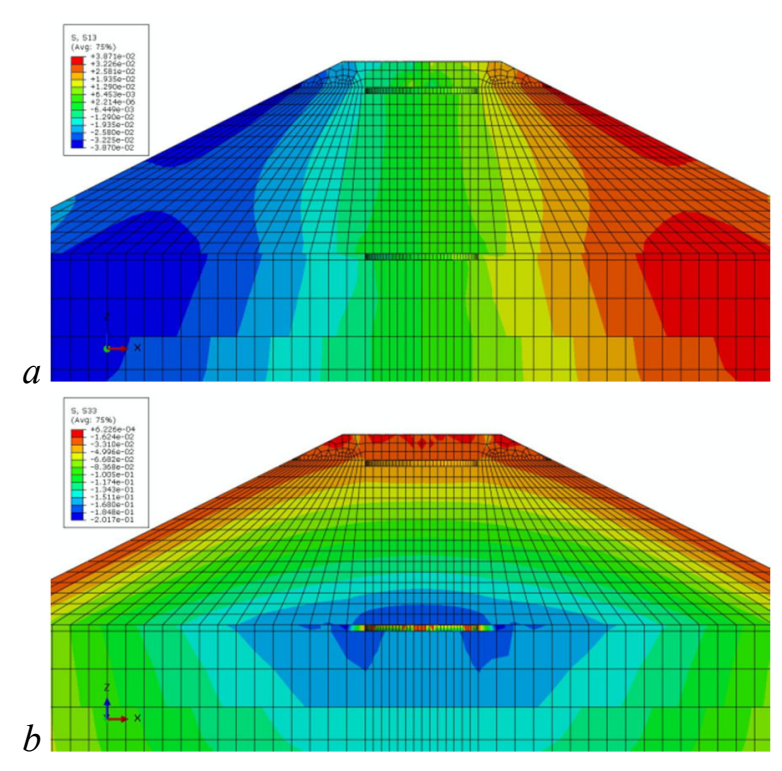

Fig. 10. Initial state of the self-weight of the mound [MPa]: a - Normal stresses in $\mathrm{z}$ direction, $\mathrm{b}$ - Tangential stresses

Statue construction weight - induced load.

The soil of the mound plays a critical role in the distribution and transfer of the load to the bedrock. The load from the statue is transferred through the structure of the slabs and the lateral surface of the piles to the surrounding soil of the mound. This allows the load to be distributed over a larger area and reduces the intensity of the stresses transferred to the bedrock grounds. The middle and upper plates are joined together by piles and a central column, forming a rigid spatial framework. Such design increases overall stability of the structure, but leads to a reduction of the load on the soil between the plates.

Applying vertical load $\mathrm{Fv}$ in the eccentrical fashion resulted in the non-uniform deformation of the soil (Fig. 11). In the zones of the middle and upper plates, the maximum compressive stresses has increased to about $80 \mathrm{kPa}$ while on the opposite side of the plates stress was close to zero (Fig. 11, b). The maximum difference in the upper slab settlements did not exceed $2.2 \mathrm{~mm}$.

The uneven load affected the loading taken by piles. Analysis of the force distribution along the piles showed that the greatest forces occurred in the area between the middle and upper slabs (Fig. 12). The maximum 
forces reached values of about $400 \mathrm{kN}$ (No $5,6)$ from the eccentricity side. On the opposite side (No 2, 3) forces were smaller by $30 \%$.

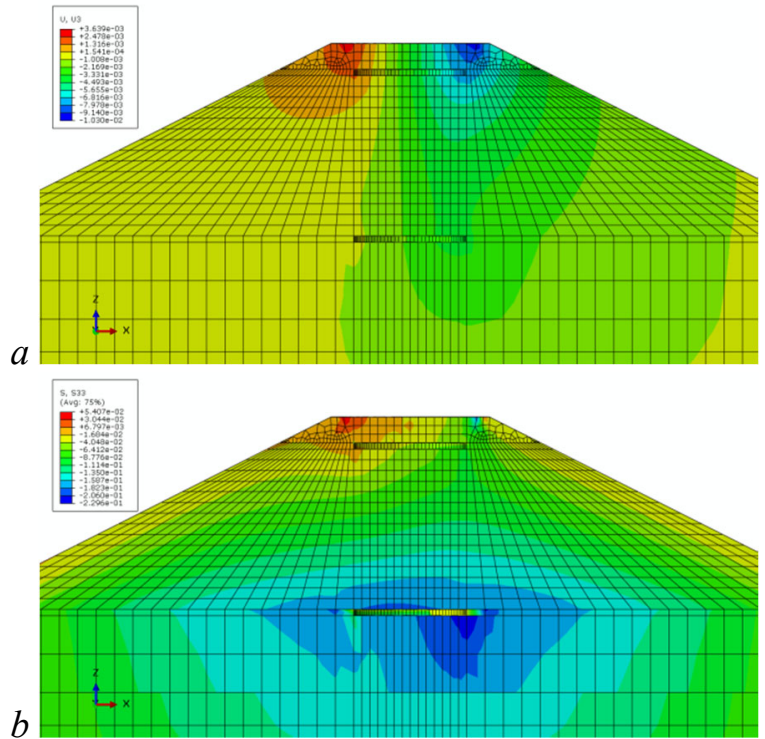

Fig. 11. Vertical displacement [m] (a) and vertical stresses $[\mathrm{MPa}](\mathrm{b})$ in the soil mound due to the dead load of Statue $\left(\mathrm{F}_{\mathrm{v}}\right)$

It should be noted that the forces at the middle plate were higher than at the pile heads. In the zone between the middle and lower plates, the rigidity of the foundation was reduced. This allowed the soil of the mound to take a greater part in the redistribution of the load from the foundation. As it is seen in the chart (Fig. 12, a), underneath the middle plate, the forces in the most loaded piles are reduced by $10 \%$ to a value of $370 \mathrm{kN}$ while forces in less loaded piles are increased by $20 \%$ to $150 \mathrm{kN}$. About $36 \%$ of the load was transmitted through the upper and middle plates. The lateral surface of the piles interacting with the soil of the mound has transferred part of the load to the soil and it results in a fall in axial forces in the piles with increasing depth (Fig. 12 , a). As a result, lower plate has taken at most $45 \%$ of the load from the monument while more than half of the weight-induced load was transferred to the bedrock through the mound. In the zone below the lower plate, the stresses increased by $10 \%$, which has not resulted in any significant changes in the over- all behaviour of the foundation-base system as a whole.

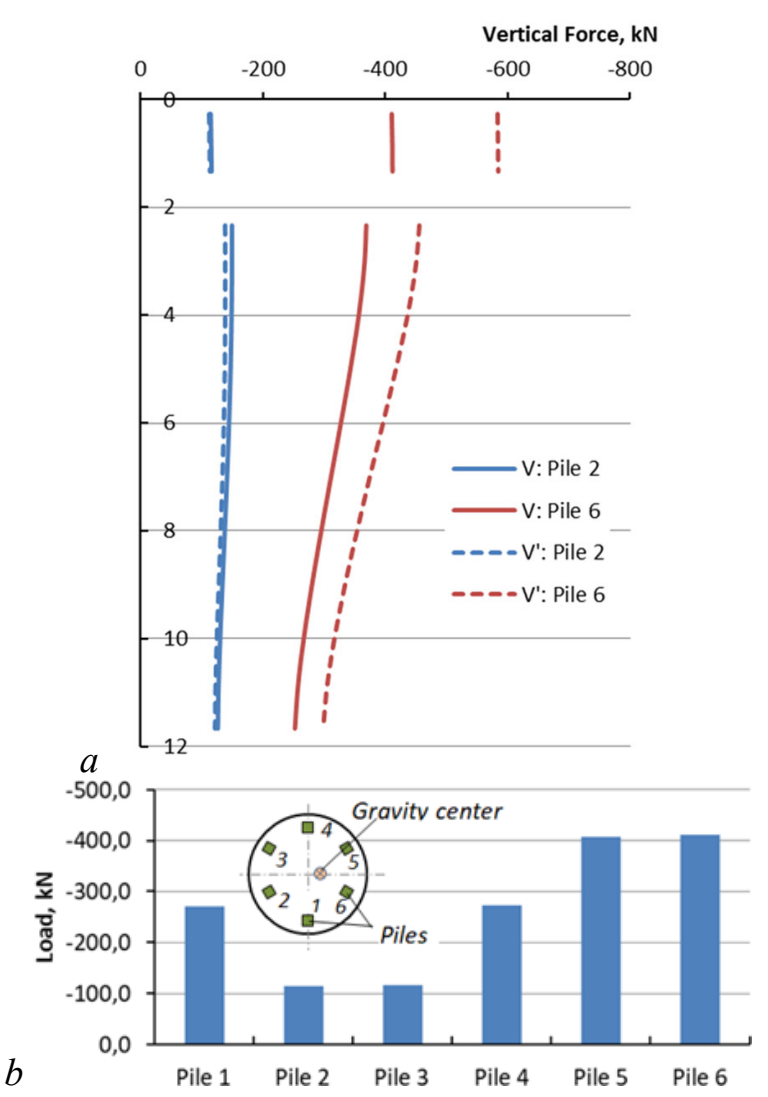

Fig.12. Distribution of vertical forces in piles: $\mathrm{a}-$ along the piles, $b-$ in the piles head

The soil in the zone of the top foundation slab can be prone to erosion, which would lead to either appearance of weak soils or cavities under the slab. To assess this behaviour, a simulation of the foundation work was performed under condition of a loose contact of the soil with the upper plate. For this purpose, the hardness of the soil layer under the upper slab was assumed equal to $5 \mathrm{MPa}$ (conditionally strongly compressible soil).

The inability of the load transfers through the upper plate sole resulted in the redistribution of forces in the foundation. According to the simulation, the load transferred through the piles in the zone of the upper and middle slabs has increased from $64 \%$ to $80 \%$ (Fig. 12, a). The remaining load was transferred directly through the central column to the middle slab. It should be noted that the changes (increases) of forces in piles were mainly appeared from 
the side of the eccentricity. The maximum compression force increased by $30 \%$ and reached $600 \mathrm{kN}$. In less loaded piles, the forces remained practically unchanged.

To effectively use the mound, the load must be transferred from the top. The absence of dense soil (in the compressed state) between the upper and middle plates did not allow effective use of the surrounding soil at this level. The load transfer through piles and columns to the middle plate led to a higher stress intensity under the sole. However, the total transmitted load through the slab to the ground decreased by $15 \%$ and amounted to about $20 \%$ of the load of the statue's own weight. The loading of the lower plate also grows slightly. However due to the pile skin resistance, only about $50 \%$ of the total load was transferred to the soil through the pile toe - preventing significant changes in the interaction of the structure with soil.

Thus, the presence of a middle slab in the upper part allows to transfer from 20 to $35 \%$ of the vertical load of the statue to the top of the mound. The loose connection between the upper slab and the mound soil results in the increased forces on the pile section between the middle and upper slabs, but does not significantly change the overall system interaction.

Wind-induced horizontal load.

The statue is located in an open area, so it is subject to considerable wind load. Due to a high altitude, this leads to the appearance of the moment $\mathrm{M}$ with value around $11250 \mathrm{kNm}$ on the foundation level. Winds mostly act from the front of the statue. However, in order to assess the most unfavourable conditions, the direction of the wind load was reversed and taken in accordance with the eccentricity of the vertical load (Fig. 8).

Horizontal component of the load led to an increase in the role of the foundation up to 6 times. The maximum difference in the sediments of the upper plate was about $13 \mathrm{~mm}$. There were also tensile stress zones underneath the foundation slabs. Due to the high rigidity of the foundations, the soil between the upper and middle plates practically did not participate in the load distribution. This has evoked vertical compressive stresses to be present under less than $50 \%$ of the upper plate surface, with their level reaching $17 \mathrm{kPa}$ (Fig. 13 , a). In the middle slab due to stretching of the soil, the effective area of the sole decreased by about $30 \%$. Due to the piles being joined at the bottom, soil deformation between the plates was significantly constrained and did not allow to apply substantial load to the soil in the compression zone in the upper part of the mound. The level of vertical compression stresses under the middle plate was about 70 to $90 \mathrm{kPa}$. Thus, the bulk of the load was transferred to the piles and the lower plate. Also, zones with concentration of shear stresses were also recorded with values of about 60 $80 \mathrm{kPa}$ (Fig. 13, b), which could lead to plastic deformations. However, taking into account that at this stage the main load is transferred through the piles, the appearance of plastic deformations will not lead to significant changes in the foundation behaviour.

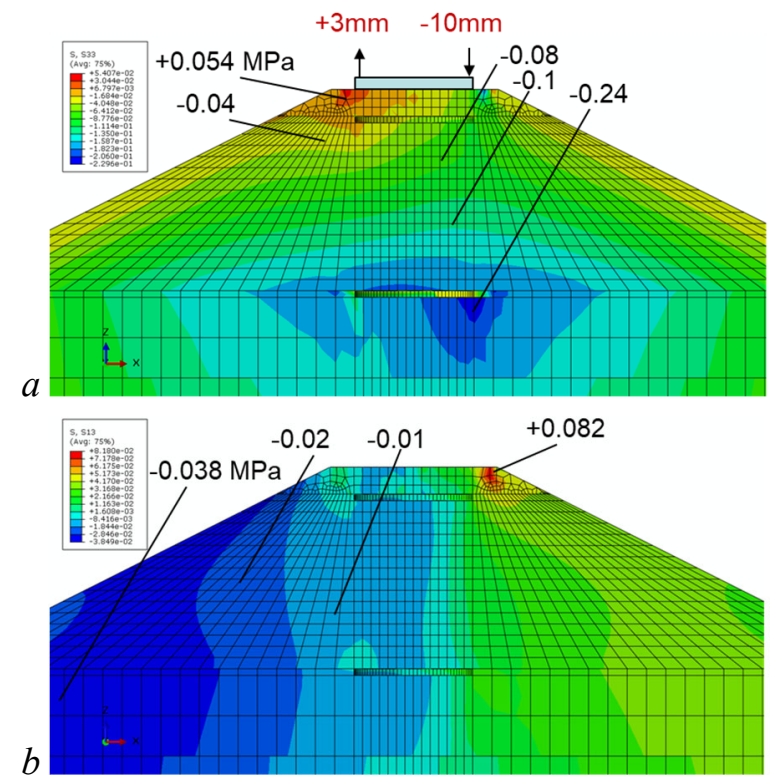

Fig. 13. Distribution of stress $[\mathrm{MPa}]$ state of the mound due to vertical and horizontal load of Statue $\left(F_{v}+F_{h}\right)$ : a - normal stress $\sigma_{33}$ with vertical displacement of foundation, $\mathrm{b}$ - shear stresses $\sigma_{13}$

Decrease in soil work in the upper zone of the mound has significantly influenced the growth of forces in piles. The action of the 
moment led to the appearance of stretches in the piles on one side and a more than two-fold increase in the compressive forces within the opposite side. The maximum compression forces were about $1130 \mathrm{kN}$, and the tensile forces were about $600 \mathrm{kN}$, located on the section between the upper and middle plates (Fig. 14). Below the middle "plate" the values of axial forces has decreased by $18 \%$ and $30 \%$, respectively. The horizontal load also led to an increase in the transfer of load to the mound soil through the lateral surface of the piles. This has allowed to distribute the load more evenly throughout the volume of the mound and to reduce the load of the lower plate by piles by an average of about $10 \%$. It is assumed that the mound soil is compacted and have complete contact with the surface of the piles.

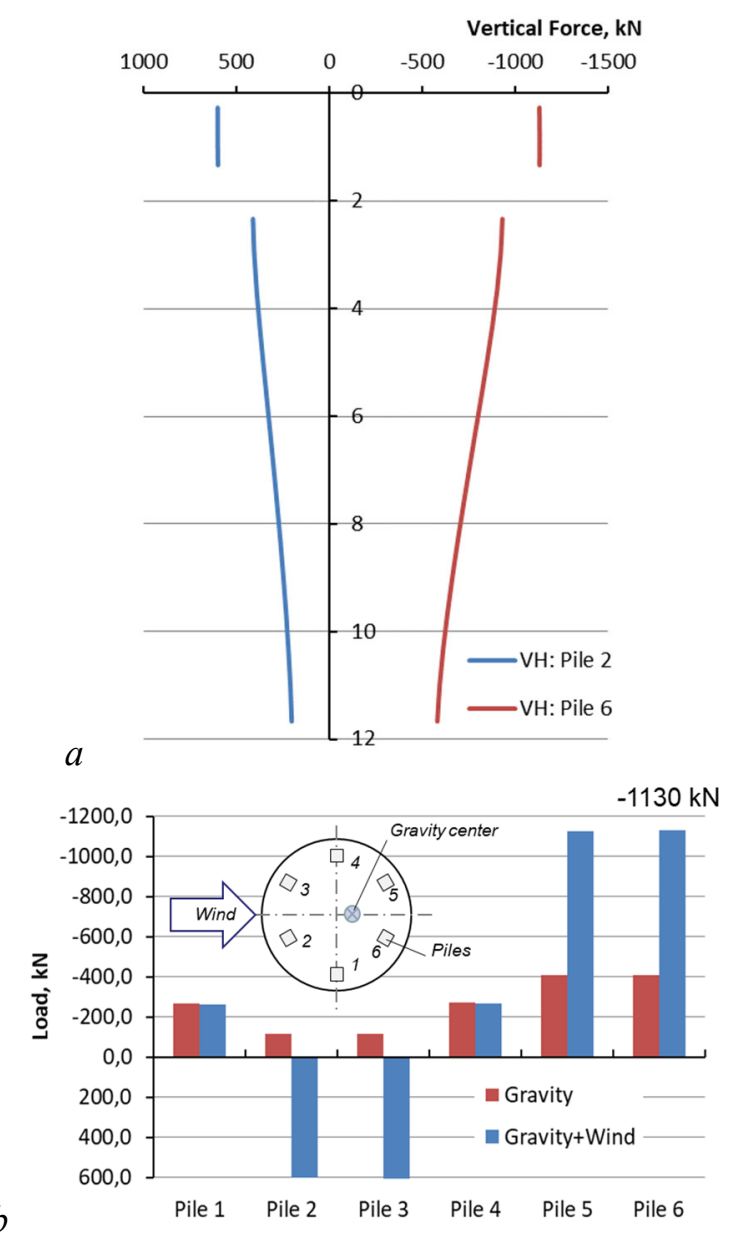

Fig.14. Distribution of vertical forces in piles due to vertical and horizontal load $\left(\mathrm{F}_{\mathrm{v}}+\mathrm{F}_{\mathrm{h}}\right)$
Uneven load transfers near the soles of the piles led to unloading of the slab on one side and an increase in vertical compressive stresses (by about 20\%) from the opposite side (Fig. 13, a). The stress values have varied between $0.19 \mathrm{MPa}$ and $0.24 \mathrm{MPa}$ (normal stress) with a shear stress level of up to $40 \mathrm{kPa}$. Plastic deformations typically do not appear in this state. However even when present they would be highly localized and will not change overall foundation behaviour.

It should be noted that the behaviour of the statue foundation largely depends on the state of the mound and the degree of compaction of its grounds during the construction. The main load is taken by piles. Particular attention should be given to the area between the upper and middle slabs, where the stress level may change periodically depending on the wind load.

\section{CONCLUSIONS}

Based on the results of the performed research, we have reached the following conclusions.

1. In the analysed case of piles-plates foundations, soils of the mound play important role in taking loads of the statue, spreading them and safely transferring to the undisturbed level of natural soils.

2. The intermediate and upper plates make the spatial rigidity of the foundations and ensure a transfer of the load to the soil base.

3. The wind load causes a slight inclination of the foundation, but also increases the pile-soil interaction with the side surface and allows distributing the load more evenly.

4. It follows from the results of numerical simulations that piles/columns take as much as $64 \%$ of the whole vertical load. At the same time soils of the mound take through the side surface of piles nearly $20 \%$ of the whole vertical load. 


\section{REFERENCES}

1. Tallest Jesus statue - Christ the King Monument sets world record. World Record Academy.com

2. Marcinowski J. (2011). Short story of a huge undertaking (in Polish), Published by University of Zielona Góra.

3. Grosel J., Sawicki W., Marcinowski J., Wójcicki Z. (2015). Monument of Christ the King - OMA study. In: 6th International Operational Modal Analysis Conference - IOMAC' 15. Gijón, Hiszpania, pp. 1-7. http://iomac.eu/iomac/2015/pdf/212 Paper_Gro sel.pdf

4. Grosel J., Sawicki W., Marcinowski J., Wójcicki Z. (2017). OMA Post-renovation study of the Christ the King monument preparation for wind-load analysis. In: 7th International Operational Modal Analysis Conference IOMAC 2017. Ingolstadt, Niemcy, 2017 .- Aachen : Shaker Verlag, 2017 .- Messtechnik und Sensorik, pp. 150-153.

5. Grosel J., Marcinowski J., Sakharov V. (2019). Numerical modelling of the structurefoundation system on the basis of vibrations measurements. Challenges in Geotechnical Engineering - CGE 2019. Zielona Góra, Polska Zielona Góra, p 16.

6. Grosel J., Sawicki W., Wojcicki Z., Marcinowski J., Sakharov V. (2019). OMA as a tool for nonlinearity detection. $8^{\text {th }}$ International Operational Modal Analysis Conference - IOMAC' 19. Copenhagen, Dania Amsterdam: Elsevier, 2019, pp. 63-70

7. Shen S.L., Chai J.C., Miura N. (2001). Stress Distribution in Composite Ground of ColumnSlab System Under Road Pavement, in: Computational Mechanics-New Frontiers for the New Millennium, S. Valliappan and N. Khalili, editors, pp. 485-490. 